\title{
Mapping of resection margins of oral cancer for p53 overexpression and chromosome instability to detect residual (pre)maligant cells.
}

\author{
Citation for published version (APA): \\ van der Toorn, P. P., Veltman, J. A., Bot, F. J., de Jong, J. M. A., Manni, J. J., Ramaekers, F. C. S., \& \\ Hopman, A. H. N. (2001). Mapping of resection margins of oral cancer for p53 overexpression and \\ chromosome instability to detect residual (pre)maligant cells. Journal of Pathology, 193, 66-72. \\ https://doi.org/10.1002/1096-9896(2000)9999:9999<::AID-PATH785>3.0.CO;2-J
}

\section{Document status and date: \\ Published: 01/01/2001}

DOI:

10.1002/1096-9896(2000)9999:9999<::AID-PATH785>3.0.CO;2-J

\section{Document Version:}

Publisher's PDF, also known as Version of record

\section{Please check the document version of this publication:}

- A submitted manuscript is the version of the article upon submission and before peer-review. There can be important differences between the submitted version and the official published version of record.

People interested in the research are advised to contact the author for the final version of the publication, or visit the DOI to the publisher's website.

- The final author version and the galley proof are versions of the publication after peer review.

- The final published version features the final layout of the paper including the volume, issue and page numbers.

Link to publication

\footnotetext{
General rights rights.

- You may freely distribute the URL identifying the publication in the public portal. please follow below link for the End User Agreement:

www.umlib.nl/taverne-license

Take down policy

If you believe that this document breaches copyright please contact us at:

repository@maastrichtuniversity.nl

providing details and we will investigate your claim.
}

Copyright and moral rights for the publications made accessible in the public portal are retained by the authors and/or other copyright owners and it is a condition of accessing publications that users recognise and abide by the legal requirements associated with these

- Users may download and print one copy of any publication from the public portal for the purpose of private study or research.

- You may not further distribute the material or use it for any profit-making activity or commercial gain

If the publication is distributed under the terms of Article 25fa of the Dutch Copyright Act, indicated by the "Taverne" license above, 


\title{
Original Paper
}

\section{Mapping of resection margins of oral cancer for p53 overexpression and chromosome instability to detect residual (pre)malignant cells}

\author{
Peter-Paul G. van der Toorn', Joris A. Veltman², Fredrik J. Bot³ , Joseph M. A. de Jong', Johannes J. Manni²*, \\ Frans C. S. Ramaekers ${ }^{4}$ and Anton H. N. Hopman ${ }^{4}$ \\ I Radiotherapeutic Institute, Limburg, The Netherlands \\ ${ }^{2}$ Department of Otorhinolaryngology and Head and Neck Surgery, University Hospital Maastricht, The Netherlands \\ ${ }^{3}$ Department of Pathology, University Hospital Maastricht, The Netherlands \\ ${ }^{4}$ Department of Molecular Cell Biology and Genetics, University of Maastricht, The Netherlands
}

* Correspondence to: Johannes J. Manni, Department of Otorhinolaryngology and Head and Neck Surgery, University Hospital Maastricht, PO Box 5800, 6202 AZ Maastricht, The Netherlands. E-mail: J.J.Manni@kno.azm.nl

Received: 15 May 2000

Accepted: 8 August 2000

Published online:

16 November 2000

\begin{abstract}
Oral squamous cell cancers (OSCCs) have a high local recurrence rate, partly due to problems in the recognition of minimal residual disease. The use of molecular markers is shown to increase the sensitivity of detection of residual malignant cells in tumour margins of OSCC. p53 immunohistochemistry was combined with in situ hybridization for chromosomes 1 and 7 to determine the presence of genetically unstable cells in resection specimens of OSCC containing invasive cancer. An increased frequency of genetically aberrant cells was observed, as detected by p53 overexpression and/or aneusomy, with histological progression of normal mucosa via hyperplasia to dysplasia. Of clinical importance was the finding that 11 of 20 resection margins, all of which were initially diagnosed as being tumour-free, were found to contain genetically aberrant (pre)malignant cells. In these areas, closer histological examination of the genetically aberrant compartment within these margins often also revealed small dysplastic areas that were missed in the initial diagnosis, showing that this genetic approach can assist in diagnosis. Copyright (C) 2000 John Wiley \& Sons, Ltd.
\end{abstract}

Keywords: oral squamous cell carcinoma; chromosome aberrations; in situ hybridization; p53; minimal residual disease; genetic instability

\section{Introduction}

The acquisition of genetic instability is an essential step during carcinogenesis $[1,2]$. In most tumours, including oral squamous cell carcinomas (OSCCs), such a genomic change results in numerical and structural chromosome alterations $[3,4]$. Although the molecular basis of this chromosomal instability is as yet unknown, it has been suggested that mutations in one or more mitotic checkpoint genes cause abnormal cell division, leading to an abnormal chromosome constitution [5]. One of the candidate genes is p53, being one of the most frequently altered tumour suppressor genes known to date [6,7]. Several studies have suggested that loss of normal p53 function leads to destabilization of the genome and facilitates the development of DNA aneuploidy [8,9]. This would suggest that mutations of p53, which can be detected immunocytochemically because of its stabilization, precede the acquisition of chromosomal alterations. On the other hand, there are also indications that genetic instability can lead to loss of tumour suppressor genes such as p53 in solid cancers [10], indicating that the relationship between the two processes is still unclear. It has been shown that both p53 immunoreactivity and numerical chromosome alterations can be detected in premalignant stages of head and neck carcinogenesis [11-15], but again in these early lesions the two processes have not as yet been correlated.

In the present study, we have therefore combined p53 immunohistochemistry with chromosome in situ hybridization for the detection of numerical aberrations of chromosomes 1 and 7 in the subsequent steps of oral carcinogenesis. These chromosomes were selected on the basis of previous studies on head and neck squamous cell carcinoma (HNSCC) [4,14-16]. The correlation between the two processes was studied in resection specimens of OSCC containing invasive cancer, precursor lesions, and histologically normal mucosa.

From a clinical point of view, these markers of genetic instability may be useful for detecting the presence of minimal residual disease. It is generally believed that the presence of (pre)malignant cells in a resection margin constitutes a high risk for local recurrence, one of the major problems in head and neck oncology [17-19]. The histopathological features of premalignant lesions, which might be present within the resection margin, are very subtle and consequently, the interpretation of these features is subjective [20]. In contrast, direct visualization of genetic changes in tissue sections by either immunohistochemistry or in 
situ hybridization gives objective information on the extent of genetic damage present within these margins, and might therefore be of value in diagnosis.

\section{Materials and methods}

\section{Patient material}

Formalin-fixed, paraffin-embedded tumour specimens were obtained from 21 patients with radically resected (resection margin $>5 \mathrm{~mm}$ free of invasive carcinoma) squamous cell carcinoma of the tongue, diagnosed between 1995 and 1997. All patients had a history of smoking and drinking. Patients were treated by surgery only and classified as pT1N0M0 $(n=13)$, pT2N0M0 $(n=7)$, and pT3N0M0 $(n=1)$ (UICC, 1987). From these 21 patients a specimen representative of the free resection margin was selected after reviewing the original haematoxylin and eosin (H\&E)-stained sections. In six cases, resection margin samples also contained OSCC. Of the remaining 15 patients, seven additional OSCC specimens were selected. As a result, a total of 28 specimens were studied, 15 containing a free margin only and 13 containing both tumour and adjacent epithelium. As a control group, four patients with a benign lesion of the tongue were included (two hyperkeratotic papillomas and two fibromas). From all cases, $4 \mu \mathrm{m}$ thick sections were used for detailed histological examination, p53 immunohistochemistry, and chromosome in situ hybridization.

\section{Histological examination}

All specimens were H\&E-stained and subsequently reviewed by an experienced pathologist (FJB). Normal, hyperplastic, dysplastic, carcinoma in situ (CIS), and tumour areas, if present, were identified and marked on the slide for detailed comparisons with the genetic data. The classification of hyperplasia, mild, moderate and severe dysplasia/carcinoma in situ, or infiltrative carcinoma was undertaken as follows. Hyperplasia is defined as keratosis and acanthosis with at most slight atypia of the basal cell layer. Dysplasia shows, in addition, more than just slight individual cell atypia, increasing keratosis and sometimes parakeratosis. This group could be subdivided into mild and moderate dysplasia, but the cases were considered as a single group, for reasons of simplicity; this is clinically justified, because mild and moderate dysplasia would not lead to therapeutic intervention, but only followup, while severe dysplasia/carcinoma in situ definitely would. Severe dysplasia/carcinoma in situ is characterized by increasing, often full thickness cell atypia, loss of polarity, and frequent mitoses, while lacking infiltrative growth. Carcinoma is then defined as showing infiltrative growth with an accompanying stromal reaction. Normal epithelium is regular nonkeratinizing squamous epithelium without the features mentioned above. In all cases, the changes described refer to abnormalities involving the complete epithelial cell layer. Small areas of atypical cells do not fit into this classification.

In addition to the standard histological examination performed at the beginning of this study, a detailed histological examination was performed after the chromosome in situ hybridization and p53 analyses were completed, and all tissue areas containing genetic abnormalities had been precisely mapped. During reexamination, the pathologist focused on the areas containing genetic abnormalities. These regions were often very small, consisting in some cases of no more than $10-20$ cells.

\section{In situ hybridization}

In situ hybridization (ISH) was essentially performed using a recently optimized protocol and evaluated according to well-established criteria [21,22]. Briefly, after deparaffinization, the $4 \mu \mathrm{m}$ thick sections were pretreated with $85 \%$ formic acid containing $0.3 \%$ $\mathrm{H}_{2} \mathrm{O}_{2}$, followed by incubation at $80^{\circ} \mathrm{C}$ in $1 \mathrm{M}$ sodium thiocyanate. After digestion with pepsin $(4 \mathrm{mg} / \mathrm{ml}$ in $0.02 \mathrm{~N} \mathrm{HCl}$ ), individual sections were hybridized with a centromere-specific probe for either chromosome 1 or chromosome 7 [23], labelled with biotin-11-dUTP (Boehringer, Mannheim, Germany). Immunocytochemical detection of hybrids was performed by the standard avidin-biotin complex (ABC) procedure (Vectastain, Vector Laboratories, Burlingame, CA, USA). Peroxidase activity was detected using diaminobenzidine (DAB) $/ \mathrm{H}_{2} \mathrm{O}_{2}$. Sections were counterstained with haematoxylin and mounted in Entellan (Merck, Darmstadt, Germany). Evaluation was performed qualitatively by independent detailed analys is of the complete epithelium by two of us (PPGvdT and JAV). The sections were analysed to identify whether nuclei containing aberrant chromosome copy numbers were present. Histologically described epithelial areas were classified as either disomic (normal), when no nuclei with three or more ISH signals were observed, or aneusomic (abnormal), when multiple nuclei with three or more ISH signals were present for one or both chromosomes.

\section{p53 immunohistochemistry}

An immunohistochemical assessment of $\mathrm{p} 53$ protein overexpression was performed on $4 \mu \mathrm{m}$ sections from paraffin-embedded tissue. After deparaffinization, the sections were pretreated with $0.3 \% \mathrm{H}_{2} \mathrm{O}_{2}$ in methanol to quench endogenous peroxidase activity. Antigen retrieval was performed by microwave heating in $0.01 \mathrm{M}$ citrate buffer (pH 6.0). Both normal and mutant $\mathrm{p} 53$ protein were detected using a monoclonal antibody (clone DO-7; DAKO A/S, Glostrup, Denmark). After incubation with the biotinylated secondary antibody, immunochemical detection was further performed as described for the in situ hybridization. In each analysis, a known p53-negative and p53-positive oropharyngeal tumour served as a control. Evaluation of the complete lesion was performed qualitatively by 
three of us (PPGvdT, JAV, and FJB). Histologically described epithelial areas were classified as either p53 negative, when no or only a few cells with positive nuclear staining were observed, or p53-positive, when multiple cells with positive nuclear staining were present.

\section{Results}

\section{Histological re-examination guided by genetic analysis}

Both p53 immunohistochemistry and chromosome ISH could be evaluated from the tissue sections of 20 out of 21 patients $(95 \%)$ with OSCC and in all control patients. In the control group, neither cells showing p53 overexpression, nor cells containing abnormal copy numbers of chromosomes 1 and 7 were detected after detailed analysis of the complete epithelium. p53 overexpression and abnormal chromosome copy numbers were detected frequently in the resection specimens, often in small foci which sometimes consisted of no more than 10-20 cells, located within areas that were initially diagnosed as normal or hyperplastic. For this reason, the specimens were re-examined histologically, with a special focus on the genetically aberrant tissue compartments, in contrast to the results from the initial histological examination, in which dysplasia was identified in only three samples, re-examination revealed dysplasia in 14 samples.

\section{Correlation between histology, genotype, and p53 status}

Table 1 summarizes in detail the results for p53 immunohistochemical staining and chromosome ISH for each of the 20 patients with OSCC. Results for chromosomes 1 and 7 are combined in this table. As a typical example, the resection margin of case 10 contains histologically normal, hyperplastic, and dysplastic areas, whereas an additional sample of the same case contains the carcinoma adjacent to regions with hyperplasia and dysplasia. The normal and the hyperplastic regions are genetically normal, with no p53 overexpression and no nuclei with more than two copies of chromosomes 1 and 7, whereas the dysplastic areas and the carcinoma region show both p53 overexpression and abnormal chromosome copy numbers. In some other cases, the relationship between histology, p53 overexpression, and the presence of chromosomal alterations is less clear. For example, in case 19, p53 overexpression is present in a hyperplastic area without chromosomal abnormalities. In contrast, the carcinoma region of this case contains numerical aberrations for both chromosomes, but does not show $\mathrm{p} 53$ overexpression.

Figure 1 illustrates typical p53 staining and ISH results in the OSCC and in part of the resection margin of case 16. As can be seen in this figure, the tumour cells are p53-positive and contain multiple copies of
Table I. Results of the p53 and ISH analyses of 20 patients with OSCC

\begin{tabular}{|c|c|c|c|c|c|c|c|c|}
\hline \multirow{3}{*}{$\begin{array}{l}\text { Patient } \\
\text { No. }\end{array}$} & \multicolumn{8}{|c|}{ Histological classification } \\
\hline & \multicolumn{2}{|c|}{ Normal } & \multicolumn{2}{|c|}{ Hyperplasia } & \multicolumn{2}{|c|}{ Dysplasia } & \multicolumn{2}{|c|}{ CIS/OSCC } \\
\hline & p53 & ISH & p53 & ISH & p53 & ISH & p53 & ISH \\
\hline 1 & $N$ & $N$ & $N$ & $N$ & - & - & - & - \\
\hline 2 & - & - & $N$ & $N$ & - & - & - & - \\
\hline 3 & - & - & $N$ & $N$ & - & - & - & - \\
\hline 4 & - & - & $N$ & $N$ & - & - & $N$ & $N$ \\
\hline $5 a$ & $N$ & $N$ & - & - & - & - & - & - \\
\hline$b$ & $N$ & $N$ & $N$ & $N$ & - & - & $N$ & $N$ \\
\hline 6 & $N$ & $N$ & - & - & - & - & $N$ & $A$ \\
\hline $7 \mathrm{a}$ & $N$ & $N$ & - & - & - & - & - & - \\
\hline$b$ & $N$ & $N$ & $N$ & $N$ & $N$ & $N$ & $N$ & A \\
\hline $8 a$ & $N$ & $N$ & - & - & - & - & - & - \\
\hline$b$ & $N$ & $N$ & - & - & - & - & A & A \\
\hline $9 a$ & - & - & $N$ & $N$ & A & A & - & - \\
\hline$b$ & - & - & $N$ & $N$ & A & A & A & A \\
\hline $10 \mathrm{a}$ & $N$ & $N$ & $N$ & $N$ & A & A & - & - \\
\hline$b$ & - & - & $N$ & $N$ & A & A & A & A \\
\hline I la & $N$ & $N$ & $N$ & $N$ & A & A & - & - \\
\hline$b$ & - & - & - & - & A & A & A & A \\
\hline 12 & - & - & $N$ & $N$ & A & $N$ & - & - \\
\hline 13 & - & - & $N$ & $N$ & A & A & - & - \\
\hline 14 & - & - & - & - & $N$ & A & $N$ & A \\
\hline $15 \mathrm{a}$ & $N$ & $N$ & - & - & - & - & - & - \\
\hline$b$ & $N$ & $N$ & $A$ & $A$ & - & - & A & A \\
\hline 16 & $N$ & $N$ & $A$ & $A$ & A & A & $A$ & A \\
\hline 17 & - & - & $N$ & $A$ & - & - & - & - \\
\hline 18 & - & - & $A$ & $N$ & A & $A$ & - & - \\
\hline 19 & - & - & A & $N$ & - & - & $N$ & A \\
\hline 20 & $N$ & $N$ & $A$ & $N$ & - & - & A & A \\
\hline
\end{tabular}

$\mathrm{CIS}=$ carcinoma in situ; $\mathrm{OSCC}=$ oral squamous cell carcinoma; $\mathrm{ISH}=$ in situ hybridization.

a, b: In seven cases, two samples taken from different locations were analysed. In these cases, sample 'a' contains the margin of resection and sample 'b' contains the tumour and adjacent mucosa.

$\mathrm{N}$ : classified as normal (p53-negative/ISH disomic); A: classified as abnorma (p53 overexpression/ISH showing abnormal chromosome copy numbers). For histological classification see the Materials and methods section.

chromosome 7. In part of the resection margin, histologically classified as hyperplasia, a distinct area with p53 overexpression and chromosome abnormalities was detected immediately adjacent to a (histologically identical) area without these genetic changes. Interestingly, in this case, the area with hyperplasia contained a maximum number of three ISH signals (indicating trisomy) for chromosome 1 and four ISH signals (indicating tetrasomy) for chromosome 7. In contrast, the tumour area showed a maximum number of six ISH signals (hexasomy) for chromosome 1 and eight ISH signals (octasomy) for chromosome 7. These data suggest that endoreduplication has occurred in the transition from hyperplasia to invasive SCC.

In total, seven out of 20 OSCC patients showed both p53 overexpression and numerical chromosomal aberrations in the resection margin. In four patients, either p53 overexpression or chromosomal alterations were detected in the resection margin, whereas the resection margin of the remaining nine patients did not show abnormalities with either technique. 

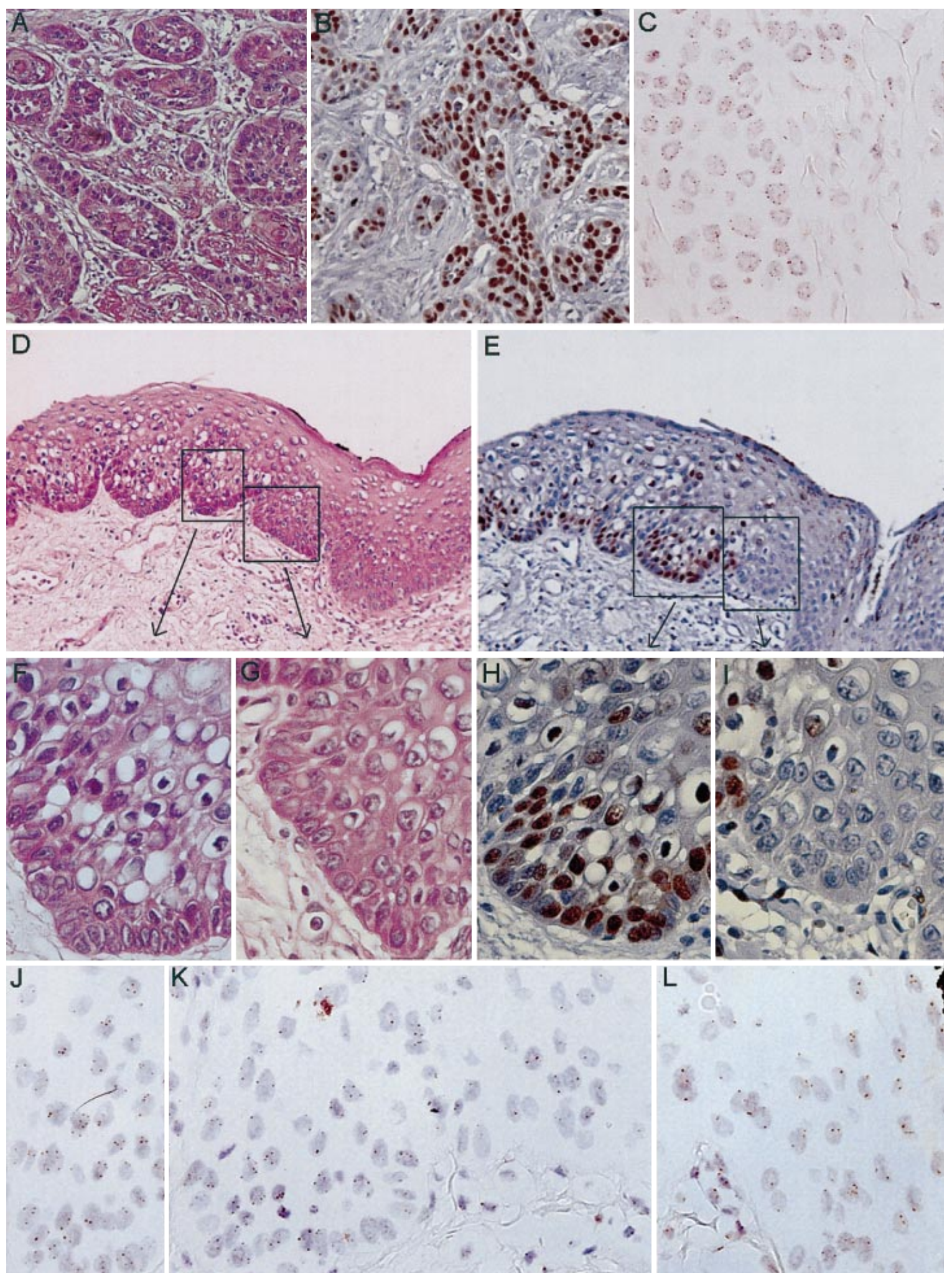

Figure I. Histology, p53 immunohistochemistry, and ISH analysis of the OSCC (A-C) and its resection margin (D-L) in case I6. (A-C) H\&E analysis of the OSCC (A), with p53 immunostaining (B) and ISH with a probe for chromosome 7 (C). The tumour cells are clearly overexpressing $\mathrm{P} 53$ and contain multiple copies (with a maximal copy number of 8 ) for chromosome 7. (D-L) H\&E analysis of the resection margin (overview in D; details in $\mathrm{F}$ and $\mathrm{G}$ ), by $\mathrm{p} 53$ immunohistochemistry (overview in $\mathrm{E}$; details in $\mathrm{H}$ and I), and ISH with a probe for chromosome 7 of the corresponding area (J, K, L). This part of the resection margin was classified as hyperplastic but shows both overexpression of $\mathrm{p} 53$ and numerical aberrations for chromosome 7 in part of the epithelium (in this case, with a maximal copy number of 4), whereas an adjacent part is negative for $p 53$ staining and contains no numerical chromosome aberrations. Note that the area showing p53 overexpression perfectly matches the area containing chromosome aberrations 


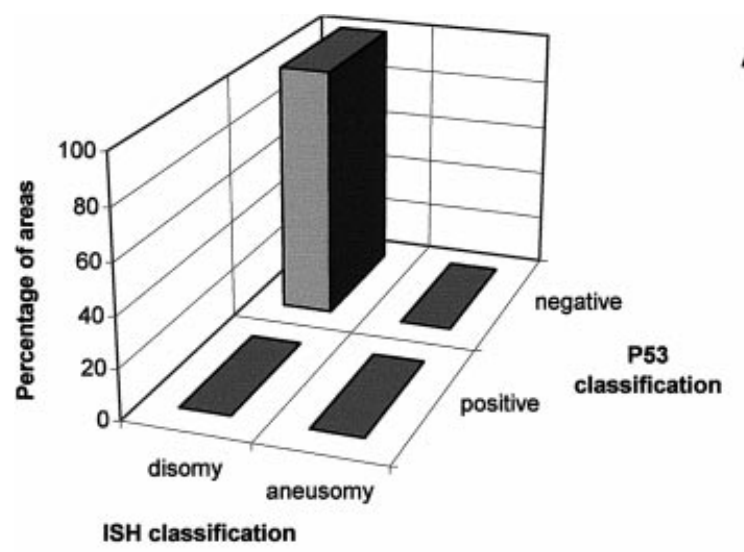

A
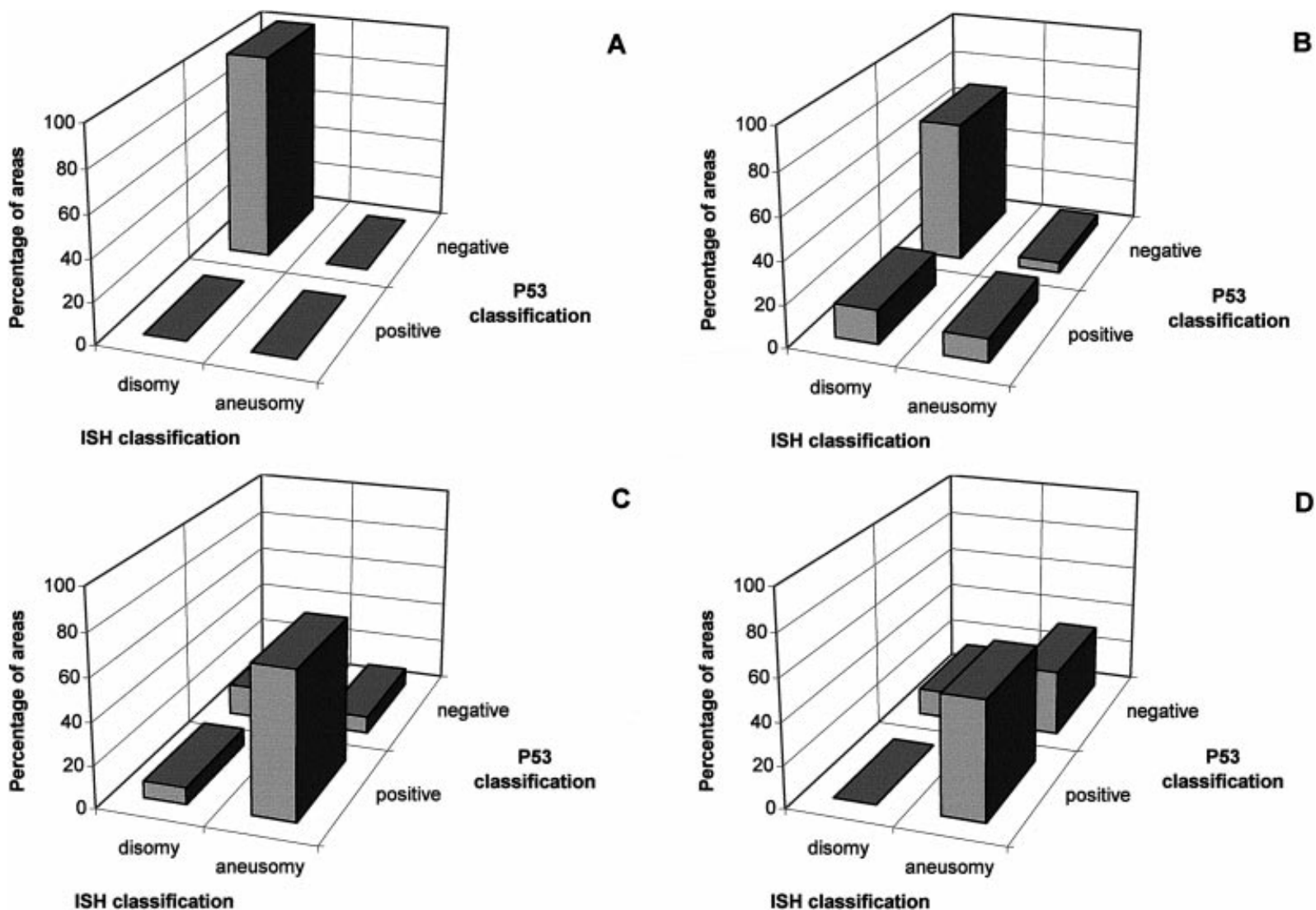

B

C

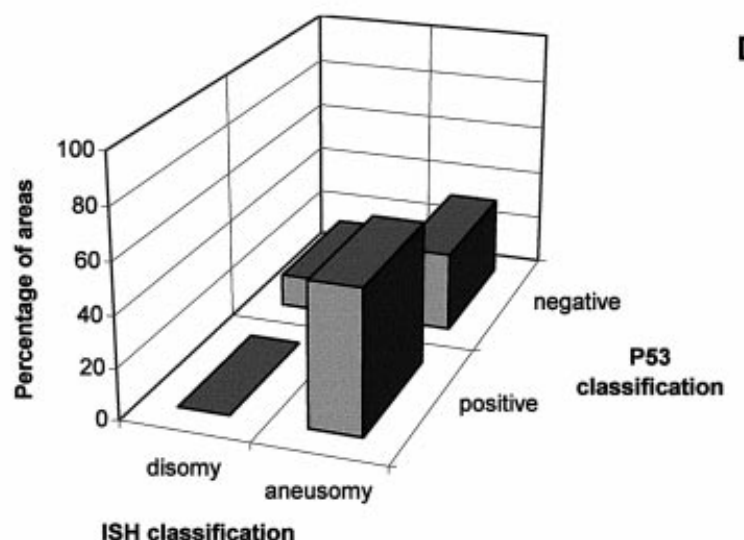

Figure 2. Frequency histograms showing the correlation between $\mathrm{p} 53$ staining and the ISH classification in different stages of oral carcinogenesis. (A) Normal tongue epithelium ( $n=14)$; (B) hyperplastic epithelium $(n=19)$; (C) dysplastic epithelium $(n=12)$; (D) $\mathrm{CIS} / \mathrm{OSCC}(n=13)$

Figure 2 shows the correlation between p53 overexpression and abnormal chromosome copy number with regard to the different histological areas present in the various samples of all 20 patients. As can be seen in this figure, neither p53 overexpression nor chromosomal abnormalities were detected in tissue compartments consisting of histologically normal epithelium. A low percentage of hyperplastic tissue compartments showed p53 overexpression and/or chromosomal abnormalities. In contrast, most dysplastic lesions (9 out of 12) showed both p53 overexpression and aberrant chromosome copy numbers. Chromosomal alterations were also present in 11 out of 13 CIS/OSCC areas, with only seven of these areas showing p53 overexpression.

\section{Discussion}

A gap appears to exist between the histopathological diagnosis of the resection margin of tumour specimens and the patient's clinical course. Depending on the primary tumour site and stage of disease, patients with OSCC develop locoregional recurrent disease in $15-30 \%$ of cases, even when the resection margins are histopathologically free of tumour.

The introduction of molecular techniques to assess the presence of malignant cells in the resection margins can help to bridge this gap. Tumour-specific chromo- somal aberrations or DNA mutations detected in the primary tumour can, in principle, be used as markers for the detection of residual cells in the resection margins. Residual tumour cells could explain the recurrence rate and if detected in individual cases, could provide an indication for additional treatment. In this study, we used p53 immunohistochemistry and chromosome ISH to analyse in detail the resection margins of tongue carcinomas for the presence of genetically aberrant cells.

Genetically aberrant cells, as marked by either p 53 overexpression or/and aneusomies for chromosomes 1 and 7, were identified in the resection margins from 11 of 20 OSCC patients. In seven of these 11 resection margins, genetically aberrant cells were detected with both techniques, which provides a strong indication for the presence of (pre)malignant cells located in areas close to the limit of resection. In a previous study on premalignant laryngeal lesions, we detected numerical aberrations of chromosomes 1 and/or 7 in 14 out of 15 dysplastic lesions, whereas only one out of 11 hyperplastic lesions showed chromosomal alterations [15]. This finding underlines the usefulness of chromosomal alterations as markers for a dysplastic phenotype in head and neck carcinogenesis. Many authors have claimed the detection of genetic abnormalities in histologically normal mucosa adjacent to HNSCC $[11,13,14]$. Furthermore, mutated p53 genes have been 
found in tumour-distant epithelia of head and neck cancer patients as a preceding sign of overt neoplasia $[13,24,25]$.

Also during this study, we frequently identified p53 overexpression and/or chromosomal aberrations in small tissue compartments that had been classified as normal by standard histological examination. However, after review, during which the pathologist was guided by the genetic abnormalities in the tissue, the morphological features of these areas urged us to modify their classification from normal to hyperplasia, or even dysplasia. These areas were not detected by routine histological examination at the beginning of our study because of their very small size, in some cases no more than 10-20 cells. This observation underlines the subjectivity of histological examination, as recently discussed by, for example, Westra and Sidransky [20].

Our data clearly show that conclusions about DNA changes in normal mucosa can only be drawn after a detailed histological review of the genetically aberrant tissue compartments. During the second round of reviewing, guided by the p53 and ISH results, aberrant cells with cytogenetic abnormalities were detected in 11 of 20 cases, which were not recorded in the first round of reviewing. As a consequence, these lesions were 'upgraded'. One might argue whether upgrading in this way, guided by results obtained from ancillary techniques, is justified. In every case, only small numbers of cells were found with the ancillary techniques. As the classification of dysplasia relies on a mixture of cellular atypia and architectural features, small groups like these would not lead to upgrading in the histological classification system, but instead would be regarded as reactive atypia. However, they were upgraded to dysplasia with knowledge of the ISH results for the purposes of this study. It must be stressed that this procedure did not result in upgrading towards highgrade dysplasia/carcinoma in situ in any of these cases, indicating that there were no therapeutic consequences to be addressed following reclassification.

As a result of this in-depth histological examination of the resection margins, a complex pattern of histologically different areas emerged, consisting of normal, hyperplastic, and dysplastic epithelium. Neither the 14 areas with normal epithelium, nor the epithelium in four control specimens, showed chromosomal aberrations or p53 overexpression. Chromosomal aberrations were detected in $16 \%$ of the hyperplastic areas, in $77 \%$ of the dysplastic areas, and in $88 \%$ of the CIS/OSCC areas. p53 overexpression was detected in $26 \%$ of the hyperplastic areas, in $77 \%$ of the dysplastic areas, and in $56 \%$ of the CIS/ OSCC areas. Since the most common mechanism for generating genetic diversity in solid tumours involves the development of p53 abnormalities and DNA aneuploidy [26], the correlation between p53 overexpression and the acquisition of chromosomal abnormalities was examined. There are strong indications that these events are closely linked, although the molecular mechanisms underlying the development of p53-induced aneuploidy are not fully understood.

In this study, the concomitant overexpression of p53 and chromosome aneusomy detected in serial sections showed a clear correlation between positive p53 staining and the presence of chromosomal alterations in precisely mapped tissue compartments. This correlation is most evident when the results obtained in histologically normal epithelium are compared with those in dysplastic tissue compartments (Figure 2A vs. Figure 2C), which indicates that both genetic changes take place simultaneously during the histological transition from normal to dysplastic epithelium. When the results for the hyperplastic epithelium (Figure 2B), as an intermediate between normal epithelium and dysplasia, are taken into consideration, the impression is obtained that p53 overexpression precedes the occurrence of aneusomy. The finding that the link between p53 staining and chromosome alterations was not so evident in the group of CIS/OSCC areas suggests that the acquisition of genetic instability is most important in the premalignant stages of disease. It remains to be established whether the p53 gene is mutated in hyperplastic or dysplastic areas showing p53 overexpression, or whether the overexpression identified in this epithelium is merely a response of the normal non-mutated gene to DNA damage, as described [13].

In summary, we conclude that p53 overexpression and the acquisition of chromosome alterations are linked in the premalignant stages of oral carcinogenesis, leading to a genetic instability essential for malignant progression. In addition, this study showed that a combined analysis of p53 overexpression and chromosome content gives detailed information about the extent of genetic alterations present in precisely mapped epithelial areas of oral resection margins. Genetic alterations are frequently present in these margins, even in tissue compartments that do not show extensive histological changes. We therefore propose that these genetic techniques might be employed to supplement histological examination. With ISH, the nature and extent of the aberrant cells can be determined and correlated with standard histology. However, since the clinical relevance of these small groups of cytogenetically abnormal cells in the resection margins is not clear, the data would justify a larger prospective study, to correlate these findings with the clinical outcome.

\section{References}

1. Nowell PC. The clonal evolution of tumor cell populations. Science 1976; 194: 23-28.

2. Loeb LA. Mutator phenotype may be required for multistage carcinogenesis. Cancer Res 1991; 51: 3075-3079.

3. Lengauer C, Kinzler KW, Vogelstein B. Genetic instabilities in human cancers. Nature 1998; 396: 643-649.

4. Soder AI, Hopman AHN, Ramaekers FCS, et al. Distinct nonrandom patterns of chromosomal aberrations in the progression 
of squamous cell carcinomas of the head and neck. Cancer Res 1995; 55: 5030-5037.

5. Cahill DP, Lengauer $\mathrm{C}, \mathrm{Yu}$ J, et al. Mutations of mitotic checkpoint genes in human cancers. Nature 1998; 392: 300-303.

6. Hollstein M, Sidransky D, Vogelstein B, et al. p53 mutations in human cancers. Science 1991; 253: 49-53.

7. Prives C, Hall PA. The p53 pathway. J Pathol 1999; 187: $112-126$.

8. Cross SM, Sanchez CA, Morgan CA, et al. A p53-dependent mouse spindle checkpoint. Science 1995; 267: 1353-1356.

9. Fukasawa K, Choi T, Kuriyama R, et al. Abnormal centrosome amplification in the absence of p53. Science 1996; 271: 1744-1747.

10. Albertoni M, Daub DM, Arden KC, et al. Genetic instability leads to loss of both p53 alleles in a human glioblastoma. Oncogene 1998; 16: 321-326.

11. Shin DM, Kim J, Ro JY, et al. Activation of p53 gene expression in premalignant lesions during head and neck tumorigenesis. Cancer Res 1994; 54: 321-326.

12. Sauter ER, Cleveland D, Trock B, et al. p53 is overexpressed in fifty percent of pre-invasive lesions of head and neck epithelium. Carcinogenesis 1994; 15: 2269-2274.

13. Nees M, Homann N, Discher H, et al. Expression of mutated p53 occurs in tumor-distant epithelia of head and neck cancer patients: a possible molecular basis for the development of multiple tumors. Cancer Res 1993; 53: 4189-4196.

14. Voravud N, Shin DM, Ro JY, et al. Increased polysomies of chromosomes 7 and 17 during head and neck multistage tumorigenesis. Cancer Res 1993; 53: 2847-2883.

15. Veltman JA, Bot FJ, Huynen FC, et al. Chromosome instability as an indicator of malignant progression in laryngeal mucosa. $J$ Clin Oncol 2000; 18: 1644-1651.

16. Veltman JA, Hopman AHN, van der Vlies SA, et al. Doubletarget fluorescence in situ hybridization distinguishes multiple genetically aberrant clones in head and neck squamous cell carcinoma. Cytometry 1998; 34: 113-120.

17. Kowalski L, Magrin J, Waksman G, et al. Supraomohyoid neck dissection in the treatment of head and neck tumors: survival results in 212 cases. Arch Otolaryngol Head Neck Surg 1993; 119: 958-963.

18. Looser K, Shah J, Strong E. The significance of 'positive' margins in surgically resected epidermoid carcinomas. Head Neck Surg 1978; 1: 107-111.

19. Jesse R, Sugarbaker E. Squamous cell carcinoma of the oropharynx; why we fail. Am J Surg 1976; 132: 435-438.

20. Westra WH, Sidransky D. Phenotypic and genotypic disparity in premalignant lesions: of calm water and crocodiles. $J$ Natl Cancer Inst 1998; 90: 1500-1501.

21. Hopman AHN, van Hooren E, van de Kaa CA, et al. Detection of numerical chromosome aberrations using in situ hybridization in paraffin sections of routinely processed bladder cancers. Mod Pathol 1991; 4: 503-513.

22. Hopman A, Ramaekers F. Processing and staining of cell and tissue material for interphase cytogenetics. In Current Protocols in Cytometry, Robinson P (ed.). John Wiley: New York, 1998; Ch. 8.5.1-8.5.22.

23. Willard H, Waye J. Hierarchical order in chromosome-specific human alpha satellite DNA. Trends Genet 1987; 3: 192-198.

24. Brennan JA, Mao L, Hruban RH, et al. Molecular assessment of histopathological staging in squamous-cell carcinoma of the head and neck. N Engl J Med 1995; 332: 429-435.

25. Erber R, Conradt C, Homann H, et al. TP53 DNA contact mutations are selectively associated with allelic loss and have a strong clinical impact in head and neck cancer. Oncogene 1998; 16: $1671-1679$.

26. Shackney SE, Shankey TV. Common patterns of genetic evolution in human solid tumors. Cytometry 1997; 29: 1-27. 